\title{
Reelin and Notch1 Cooperate in the Development of the Dentate Gyrus
}

\author{
Mirjam Sibbe, ${ }^{1}$ Eckart Förster, ${ }^{2}$ Onur Basak, ${ }^{3}$ Verdon Taylor, ${ }^{3}$ and Michael Frotscher ${ }^{1}$ \\ ${ }^{1}$ Institute of Anatomy and Cell Biology, University of Freiburg, D-79104 Freiburg, Germany, ${ }^{2}$ Institute of Anatomy I: Cellular Neurobiology, University \\ Medical Center, D-20246 Hamburg, Germany, and 32Department of Molecular Embryology, Max Planck Institute of Immunobiology, D-79108 Freiburg, \\ Germany
}

The development of the hippocampal dentate gyrus is a complex process in which several signaling pathways are involved and likely interact with each other. The extracellular matrix molecule Reelin is necessary both for normal development of the dentate gyrus radial glia and neuronal migration. In Reelin-deficient Reeler mice, the hippocampal radial glial scaffold fails to form, and granule cells are dispersed throughout the dentate gyrus. Here, we show that both formation of the radial glia scaffold and lamination of the dentate gyrus depend on intact Notch signaling. Inhibition of Notch signaling in organotypic hippocampal slice cultures induced a phenotype reminiscent of the Reelin-deficient hippocampus, i.e., a reduced density of radial glia fibers and granule cell dispersion. Moreover, a Reelindependent rescue of the Reeler phenotype was blocked by inhibition of Notch activation. In the Reeler dentate gyrus, we found reduced Notch 1 signaling; the activated Notch intracellular domain as well as the transcriptional targets, brain lipid-binding protein, and Hes5 are decreased. Disabled1, a component of the Reelin-signaling pathway colocalizes with Notch1, thus indicating a direct interaction between the Reelin- and Notch1-signaling pathways. These results suggest that Reelin enhances Notch1 signaling, thereby contributing to the formation of the radial glial scaffold and the normal development of the dentate gyrus.

\section{Introduction}

The dentate gyrus (DG) is crucial for higher brain functions such as learning and memory, and malformation and malfunction of the DG are associated with neurological and psychiatric disorders (Raz et al., 1995; Sato et al., 2001; Haas et al., 2002; Frey et al., 2007). The DG is known for its ongoing neurogenesis throughout postnatal life (Altman, 1962; Eriksson et al., 1998; Kempermann et al., 2004).

In mice, development of the DG starts around embryonic day 10 as a proliferation of neuroepithelial cells within a small indentation of the medial wall of the lateral ventricle, the dentate notch. Through subsequent migration and continued proliferation, the stem/progenitor cell pool shifts into deeper aspects of the developing DG. One group of cells generated in this secondary proliferative matrix starts to form the granule cell layer. Another group of cells migrates into the hilus and populates this tertiary proliferative matrix. After the suprapyramidal blade of the granule cell layer has formed during embryonic development, proliferation within the secondary and tertiary matrices continues and leads to the formation of the infrapyramidal blade after birth. Stem cells of the tertiary matrix persist within the subgranular zone and

Received Feb. 26, 2009; revised March 23, 2009; accepted March 23, 2009.

This work was supported by Deutsche Forschungsgemeinschaft Grants SFB TR-3 to M.F., TA-310-2 and SFB592 to V.T., and F0 223/6-1 to E.F. M.F. was supported by the Hertie Foundation. We thank Drs. Hans Bock and Bianka Brunne for supplying Dab1 mutant mice, Bozenna Meltzer for genotyping, Drs. Matthias Kirsch and Carsten Schmidt for valuable discussions, and Dr. Sandra Dieni for critically reading this manuscript.

Correspondence should be addressed to Mirjam Sibbe, Institute of Anatomy and Cell Biology, University of Freiburg, Albertstrasse 17, D-79104 Freiburg, Germany. E-mail: Mirjam.Sibbe@anat.uni-freiburg.de.

DOI:10.1523/JNEUROSCI.0958-09.2009

Copyright $\odot 2009$ Society for Neuroscience $\quad$ 0270-6474/09/298578-08\$15.00/0 generate new granule cells throughout life. Radial glial cells have been postulated to serve two important functions in these processes, being stem cells themselves and guiding migrating granule cells (Rickmann et al., 1987; Altman and Bayer, 1990; Sievers et al., 1992; Malatesta et al., 2000; Noctor et al., 2001; Seri et al., 2001).

The signaling events governing DG development are poorly characterized. Wnt signaling and proneural transcription factors such as Neurogenin 2 and NeuroD1 are important for granule cell generation and differentiation (Galceran et al., 2000; Lee et al., 2000; Liu et al., 2000; Galichet et al., 2008). Formation of the dentate radial glial scaffold depends on Reelin, and both Reelin and SDF1 control granule cell migration (Bagri et al., 2002; Drakew et al., 2002). Reeler mutants lack Reelin, their radial glial cells undergo precocious astrocytic differentiation, and granule cells show severe migration defects being scattered throughout the dentate gyrus (Förster et al., 2002; Frotscher et al., 2003; Weiss et al., 2003). An early exhaustion of radial glial cells potentially explains the decrease in postnatal neurogenesis in Reeler mutants (Zhao et al., 2007). Radial glial cells express the Reelin receptors ApoER2 (apolipoprotein E receptor 2) and VLDLR (very low density lipoprotein receptor) (Luque et al., 2003), and Reelin stimulates and directs radial glial fiber growth (Förster et al., 2002; Hartfuss et al., 2003; Zhao et al., 2004, 2006).

Like Reelin signaling, the canonical Notch pathway controls radial glia maintenance and differentiation (Gaiano et al., 2000; Patten et al., 2003). Expression of brain lipid-binding protein (BLBP), a transcriptional target of Notch1, is reduced in the cortex of Reeler mutants, and recently, Reelin and Notch1 have been shown to interact during neuronal migration and differentiation 
in the neocortex (Sibbe et al., 2007; Hashimoto-Torii et al., 2008). Here, we studied whether Notch1 is involved in the Reelindependent development of the DG. Our results suggest that Reelin stimulates Notch1 signaling, which is important for radial glia development and maintenance in the dentate gyrus.

\section{Materials and Methods}

Animals. Reeler mutant mice (B6C3Fe strain) were identified by their well known morphological malformations in the cortex and hippocampus. Reeler mutants were crossed with Hes5-GFP transgenic animals to generate Reeler Hes5-GFP mutants. Generation of the Hes5-GFP mice has been described previously (Basak and Taylor, 2007). The genotypes of the mutants were confirmed by PCR analysis of genomic DNA, as described previously (Deller et al., 1999; Basak and Taylor, 2007). In total, 24 wild-type (wt) mice, 8 heterozygous mice $\left(\mathrm{rln}^{+/-}\right)$, and 30 Reeler mice $\left(r n^{-1-}\right), 5$ wild-type Hes5-GFP mice, and 5 Reeler Hes5-GFP mice were analyzed. All experiments were performed in agreement with the institutional guide for animal care of the University of Freiburg.

Immunostaining. Brains from 4-d-old (P4) Reeler mutant mice, heterozygous mice, wild-type littermates, and organotypic slice cultures were immersion-fixed in $4 \%$ paraformaldehyde in $0.1 \mathrm{~m}$ phosphate buffer. Brains and organotypic slice cultures were sectioned on a cryostat at $15 \mu \mathrm{m}$ or on a vibratome at $20 \mu \mathrm{m}$ (slice cultures) or $40 \mu \mathrm{m}$ (brain). Sections were then incubated in the following antibodies: anti-greenfluorescent-protein (GFP; Abcam), anti-glial fibrillary acidic protein (GFAP, rabbit polyclonal, pGFAP, DAKO; guinea pig polyclonal, pGFAP, Advanced ImmunoChemical; or mouse monoclonal, mGFAP, Sigma-Aldrich), anti-Notch1 intracellular cleaved domain (NICD; Cell Signaling Technology), anti-Notch1 Receptor (M20; Santa Cruz Biotechnology), anti-neuronal nuclear antigen (NeuN; Millipore Bioscience Reagents), anti-BLBP (Millipore Bioscience Research Reagents), and anti-Disabled 1 (Dab1; Millipore Bioscience Research Reagents). The Dab1 antibody resulted in higher than normal background staining in Dab1-deficient tissue which, however, was significantly reduced by preincubating the antibody with Dab1 knock-out tissue for $2 \mathrm{~d}$ (see Fig. $5 A, B)$. For NICD and Notch1 staining, sections received antigen retrieval before the primary antibody incubation (citrate buffer: $10 \mathrm{~mm}, \mathrm{pH}$ $\left.6.0,105^{\circ} \mathrm{C}, 15 \mathrm{~min}\right)$.

For visualization of immunostainings, Cy2-, Cy3-, or Cy5-labeled fluorescent secondary antibodies (Dianova) were used. Notch1 and NICD stainings were performed according to Tokunaga et al. (2004). NICD and Notch1 stainings were amplified by tyramide amplification (TSA; PerkinElmer). In addition, cell nuclei were stained with the fluorescent dye 4,6-diamidino-2-phenylindole (Roche Molecular Biochemicals). For Dab1/Notch1 double-labeling, the Dab1 signal was amplified by TSA, the Notch1 signal was enhanced by using a FITC-coupled antibody followed by a monoclonal anti-FITC antibody, and a Cy5-coupled antimouse antibody. In these instances, slices were preincubated in mouseon-mouse serum (Vector Laboratories) to avoid labeling of endogenous mouse IgGs. Sections were coverslipped with Moviol (Hoechst Pharmaceuticals/Sanofi-Aventis). For quantitative analysis, images were captured using a confocal microscope (LSM 510; Carl Zeiss).

Quantitative analysis of immunostainings. Quantitative measurements were performed using cellP software (Olympus-Imaging System) or ImageJ (http://rsbweb.nih.gov/ij/index.html). The intensities of NICD and GFP immunolabelings were measured as integral intensities over the entire area of the DG. Borders of the DG were identified by means of mGFAP double-staining. Four (NICD) and five (GFP) animals per genotype and five sections per animal containing the dorsal hippocampus were analyzed.

Western blotting. Protein samples were derived from 4-d-old Reeler mice and their heterozygous and wild-type littermates. To analyze NICD protein levels, three animals per genotype were used; the analysis of BLBP comprised five heterozygous animals, three wild-type mice, and seven Reeler mutants. The analysis of delta-like1 (Dll1) and Jagged1 protein levels was done on three animals per genotype. Primary antibodies were as follows: anti-NICD (Cell Signaling Technology), anti-Notch1 Receptor (M20; Santa Cruz Biotechnology), anti-Dll1 (rabbit, polyclonal; Ab- cam), anti-Jagged [rabbit, polyclonal (Nyfeler et al., 2005)]. The hippocampi were excised on cooling plates, snap-frozen in liquid nitrogen, and homogenized in $100 \mu \mathrm{l}$ cold lysis buffer (20 mM Tris buffer, $\mathrm{pH} 7.5$, $150 \mathrm{~mm} \mathrm{NaCl}, 1 \%$ Triton-X-100, 0.1\% SDS, 1 mu EDTA) in the presence of protease inhibitors (Complete; Roche Molecular Biochemicals) and phosphatase inhibitors (Pierce). Cell nuclei were destructed by sonication for $15 \mathrm{~min}$ in ice water. The homogenate was clarified by centrifugation at $14,000 \mathrm{rpm}$ for $5 \mathrm{~min}$ at $4^{\circ} \mathrm{C}$. Proteins were separated by electrophoresis on 3-8\% Tris-acetate gels (NuPage; Novex, Invitrogen) and electroblotted onto nitrocellulose membranes (Bio-Rad). Membranes were blocked in $5 \%$ nonfat dry milk in Tris-buffered saline containing $0.1 \%$ Tween 20 (TBST) for $1 \mathrm{~h}$ at room temperature. Blots were then incubated with the primary antibodies overnight at $4^{\circ} \mathrm{C}$ in milk/TBST or $5 \%$ BSA/TBST, followed by $1 \mathrm{~h}$ incubation with the appropriate secondary peroxidase-conjugated antibody (Dianova). Blots were developed using ECL reagents (Pierce), following the manufacturer's instructions.

Densitometric analysis. The bidimensional optical densities of protein bands were quantified and analyzed with TINA (Isotopenlabor Bochum, Ruhr University, Bochum, Germany). The ratios of NICD to NEXT (Notch extracellular truncation), BLBP, Dll1 and Jagged1 to Actin were calculated for standardization, and ratios between wild-type/heterozygous and mutant animals were normalized to the highest value.

Organotypic slice cultures. Slice cultures were prepared from newborn [postnatal day 0 (P0)] or P5 homozygous Reeler mutant mice and wildtype or heterozygous littermates as described previously (Zhao et al., 2004). In brief, hippocampi were excised, cut in $400 \mu \mathrm{m}$ slices, and incubated as static cultures in $1 \mathrm{ml}$ nutrition medium $(25 \%$ heatinactivated horse serum, 25\% Hank's balanced salt solution, 50\% minimal essential medium, $2 \mathrm{~mm}$ glutamine, $\mathrm{pH} 7.2$ ) at $5 \% \mathrm{CO}_{2}, 37^{\circ} \mathrm{C}$ (Stoppini et al., 1991). To inhibit the $\gamma$-secretase-dependent S3 cleavage of Notch1, the $\gamma$-secretase inhibitor $N$-[N-(3,5-difluorophenacetyl)-1alanyl]-S-phenylglycine t-butyl ester (DAPT; Sigma-Aldrich) was used (Geling et al., 2002). The activity of DAPT was tested beforehand in neural stem cell cultures (supplemental Fig. 1, available at www.jneurosci. org as supplemental material). After the first $8 \mathrm{~h}$ and then every subsequent day, the medium was replaced with media containing $10 \mu \mathrm{M}$ DAPT $(n=6)$ or $10 \mu \mathrm{M}$ dimethyl sulfoxide (DMSO; Sigma-Aldrich) for wild-type $(n=5)$ and Reeler $(n=5)$ slices.

For Reelin treatment, supernatant from Reelin-synthesizing HEK293 cells and GFP-transfected control cells (Förster et al., 2002) was concentrated and partially purified as described previously (Mayer et al., 2006). The resulting $20 \times$ concentration was diluted in culture medium to yield a $1 \times$ final concentration. Treatment started from day 0 in vitro (DIV 0 ). In addition, $1 \mu$ l medium was directly applied to each individual hippocampal culture twice a day. Slices were grown either in Reelin-containing medium plus DAPT $(n=5)$ or DMSO $(n=5)$ for control or in control medium with the addition of DMSO $(n=5)$. After a 5 d culture period, slice cultures were fixed and processed for immunostaining.

Quantitative analysis of GFAP-positive fibers. The two innermost sections of each slice culture were analyzed. To estimate the density of GFAP-positive fibers, a cycloid grid was superimposed onto the images of GFAP-stained sections, using the cycloid arc plugin in ImageJ (ImageJ, open source software; http://rsb.info.nih.gov/ij/plugins/grid-cycloidarc.html). The number of cross-sectioned GFAP-positive fibers per cycloid length was then determined. The fiber density $(L)$ was calculated using the following formula: $L=N / L_{\mathrm{T}}$ with $L_{\mathrm{T}}=2 \cdot l / p \cdot N_{\text {arc }}[N$, number of intersections; $L_{\mathrm{T}}$, total length of the test line; $l / p$, length per pixel (arc height); $N_{\text {arc }}$ number of arcs]. Normalized mean values are given.

Neural stem cell cultures. Hippocampi of 4-d-old wild-type C57BL/6J mice were removed and dissociated mechanically in Neurobasal A (Invitrogen) containing Glutamax (2 mM; Invitrogen) and $20 \mu \mathrm{l} / \mathrm{ml} \mathrm{B} 27$ (Invitrogen). For generation and expansion of neurospheres, epidermal growth factor (EGF) (PreproTech) and fibroblast growth factor-2 (FGF-2) (PreproTech) were added to a final concentration of $10 \mathrm{ng} / \mathrm{ml}$ each. The initial seeding density was $200,000 \mathrm{cells} / \mathrm{ml}$. After $6 \mathrm{~d}$ in vitro, cells were passaged for the first time with a seeding density of 50,000 cells $/ \mathrm{ml}$. From the first passage onward, neurospheres were passaged every fourth day. Experiments were performed with EGF-FGF- 
generated neurospheres between passages three and six. To inhibit the $\gamma$-secretase-dependent S3 cleavage of Notch1, DAPT (Sigma-Aldrich) was added to the medium at a final concentration of $10 \mu \mathrm{M}$. DMSO $(10 \mu \mathrm{M})$ was added to control cultures.

Statistical analysis. Statistical analysis was done using GraphPad InStat 3.0 (GraphPad Software). Student's $t$ test and ANOVA were used. Statistical significance was assumed with $p \leq 0.05$. Values are expressed as mean \pm SEM.

\section{Results}

\section{Notch 1 expression in the} developing hippocampus

Previous studies have shown that the radial glia scaffold in the DG evolves after birth in wild-type mice but fails to form in Reeler mutant mice (Weiss et al., 2003). To understand the role of Notch during Reelin-dependent radial glia scaffolding of postnatal mice, we first determined the expression of Notch 1 in the hippocampus of P4 wild-type mice (Fig. $1 A-C$ ). Immunohistochemical staining for the Notch1 receptor showed strong expression in the principal neuronal layers, namely the granule cell layer of the DG, the pyramidal cell layer of the hippocampus proper, and in the hilus (Fig. 1A). A few Notch1positive cells were also found in the strata radiatum and oriens. Notch1 immunoreactivity was generally weak in the neuropil layers. Double-labeling for BLBP, a marker of glial cells and a Notch1 target (Anthony et al., 2005), indicated that radial glial cells of the dentate gyrus express Notch1 (Fig. 1A,B). Interestingly, BLBPpositive glial cells within the strata oriens and radiatum showed only weak Notch1 expression, suggesting an inverted relationship between Notch 1 expression and astrocyte maturation (Fig. 1).

Notch 1 is activated by two, sequential proteolytic cleavages after ligand binding. The first cleavage at the S2 site is extracellular and results in a membranetethered truncated Notch (NEXT), which is subsequently cleaved at the intramembrane $\mathrm{S} 3$ site by the enzyme complex $\gamma$-secretase, thereby releasing the NICD that translocates to the nucleus. In the nucleus, NICD binds to and converts the CSL protein complex (from CBF1 in mammals, suppressor of hairless $[\mathrm{Su}(\mathrm{H})]$ in Drosophila, LAG-1 in Caenorhabditis elegans) from a transcriptional repressor into an activator of gene expression (Louvi and Artavanis-Tsakonas, 2006). To evaluate the activation of canonical Notch1 signaling, we immunostained hippocampal sections with an antibody that specifically recognizes the $\gamma$-secretase cleaved and thus active NICD (Fig. 1C-E). Activated NICD was detected in numerous cells within the dentate granule cell layer and hilus (Fig. 1D). Double-labeling revealed that presumptive radial glial cells express GFAP and have active NICD (Fig. 1C).

H
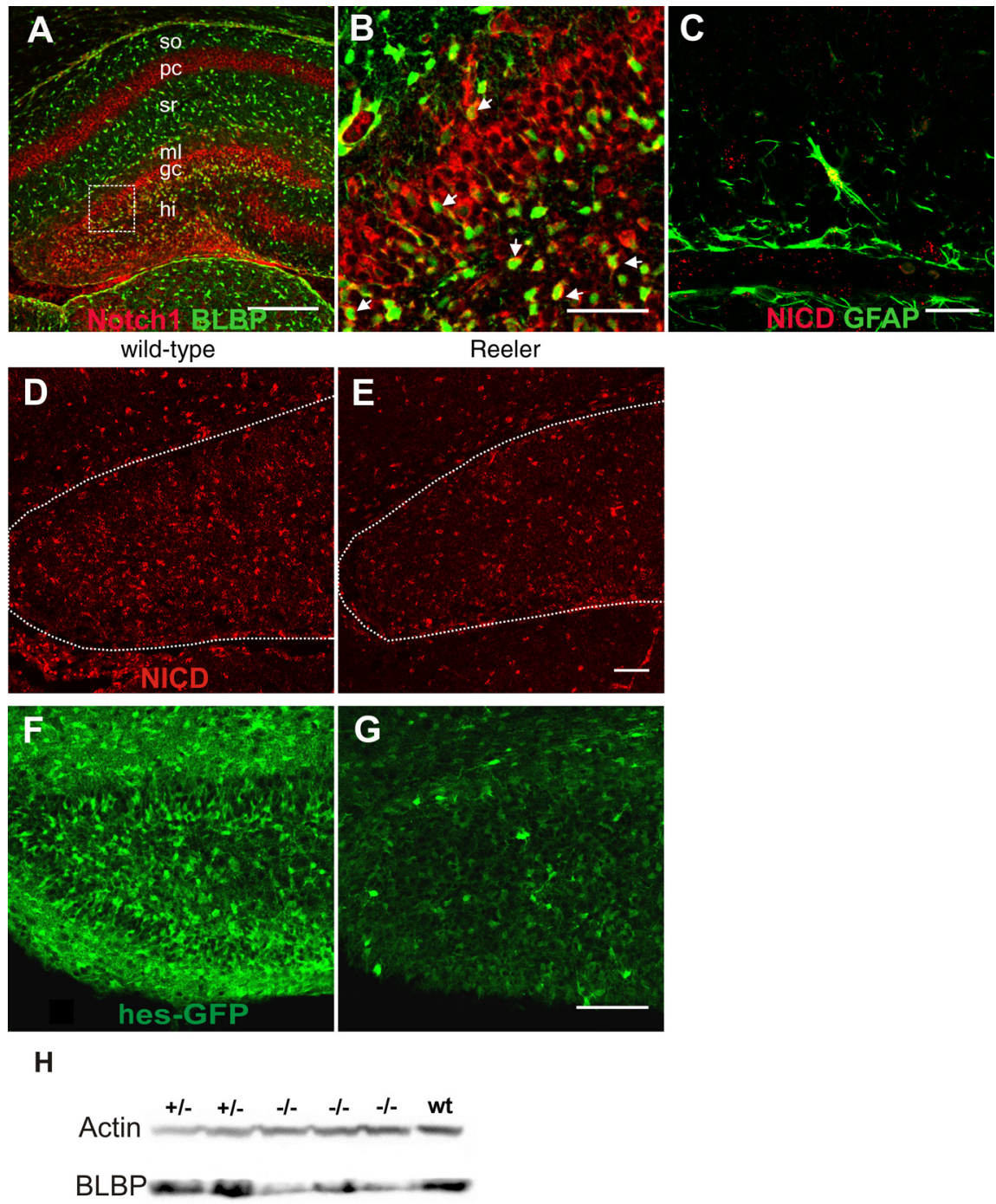

Figure 1. Notch1 signaling in wild-type and Reeler developing hippocampus. Immunohistochemical staining of P4 wild-type hippocampus. Colabeling of Notch1 (red) and BLBP (green) of the hippocampus is shown in $\boldsymbol{A}$ at low magnification. Notch1 immunoreactivity is strong in the granule cell layer of the dentate gyrus ( $g c$ ), the hilus (hi), and the pyramidal cell layer (pc) of the hippocampus proper, whereas the stratum moleculare $(\mathrm{ml})$ of the dentate gyrus is only weakly immunoreactive. Weakly Notch1positive cells were also found in strata radiatum (sr) and oriens (so). In $\boldsymbol{B}$, part of $\boldsymbol{A}$ is shown at higher magnification (boxed area). Colabeling with BLBP reveals coexpression of Notch1 and BLBP in radial glial cells of the dentate gyrus (arrows). In $C$, a section from the infrapyramidal blade illustrates expression of NICD by a GFAP-positive radial glial cell. D-G, Immunoreactivity for NICD $(\boldsymbol{D}, \boldsymbol{E}$; red) and hes5-GFP $(\boldsymbol{F}, \boldsymbol{G}$; green) in wild-type $(\boldsymbol{D}, \boldsymbol{F})$ and Reeler $(\boldsymbol{E}, \boldsymbol{G})$ dentate gyrus from P4 mice. NICD and hes5-GFP staining shows numerous positive cells in the granule cell layer and hilus of the dentate gyrus. The Reeler dentate gyrus shows significant NICD and hes5-GFP intensity compared with wild-type littermates. Images represent single laser-scanned slices in the z-plane. Scale bars: $\boldsymbol{A}, 200 \mu \mathrm{m} ; \boldsymbol{B}, 50 \mu \mathrm{m} ; \boldsymbol{C}, 20 \mu \mathrm{m} ; \boldsymbol{E}$ (for $\boldsymbol{E}, \boldsymbol{D}), 50 \mu \mathrm{m} ; \boldsymbol{G}$ (for $\boldsymbol{G}, \boldsymbol{F}$ ), $100 \mu \mathrm{m}$; white-dotted line encircles the DG. $\boldsymbol{H}$, Western blot analysis of BLBP and Actin expression in P4 wt, heterozygous $(+/-)$, and Reeler $(-/-)$ hippocampus. BLBP levels are significantly reduced in Reeler hippocampus compared with wild-type and heterozygous animals.

\section{Notch1 signaling and transcription of its target genes is diminished in the hippocampi of Reeler mice}

To study the role of Notch1 signaling in Reelin-dependent radial glia formation in the DG, we analyzed Notch1 activation in the Reeler mouse (Fig. 1D,E). The mean intensity levels of NICD immunostaining per area were significantly reduced by $20 \%$ $(p<0.05)$ in the Reeler DG $(0.79 \pm 0.05)$, compared with wildtype littermates (set 1.00 for the highest value of each simultaneously processed pair).

$B L B P$ and hes genes are transcription targets induced by NICD/CSL binding (Kageyama and Ohtsuka, 1999; Anthony et al., 2005; Louvi and Artavanis-Tsakonas, 2006). We analyzed 
hippocampal lysates for BLBP protein levels by immunoblotting to study Notch 1 activity (Fig. $1 H$ ). After standardization to Actin, the mean level of BLBP in the hippocampi of wild-type/ heterozygous mice was $0.56 \pm 0.12$ and was significantly reduced $(p<0.05)$ to $0.22 \pm 0.06$ in lysates of hippocampi from Reeler mice.

To verify the potentially reduced Notch 1 signaling in Reeler mutants, we analyzed hes5 expression. The helix-loop-helix transcription factor Hes 5 is a well described Notch1 target (Kageyama and Nakanishi, 1997). We used an established Notch reporter mouse line (Hes5-GFP) in which GFP is expressed under the control of the hes5 regulatory elements (Basak and Taylor, 2007). GFP expression in this line is dependent on, and restricted to, cells with canonical Notch activity. The majority of these cells were previously shown to exhibit stem cell characteristics (Basak and Taylor, 2007). This reporter mouse enabled us to localize hes5-expressing cells in the postnatal DG. Labeling with the glial markers BLBP showed numerous double-labeled cells and confirmed the glial identity of hes5-expressing cells in the wild-type DG (O. Basak and V. Taylor, unpublished data). Intensity measurements of GFP-immunostained sections revealed a significant reduction of GFP labeling per area in the DG by $\sim 50 \%$ in Reeler mutants (Fig. $1 G$ ), compared with their wild-type littermates (Fig. $1 F$ ), further affirming altered canonical Notch1 signaling in the absence of Reelin (wt, $0.93 \pm 0.07$; Reeler, $0.52 \pm 0.09$; Student's $t$ test; $p<0.05)$.

\section{Expression levels of Notch1 ligands are not altered in the Reeler hippocampus}

The observed reduction in Notch 1 activation could result from a reduced expression of Notch1 ligands. Therefore, we measured expression levels of the two Notch1 ligands, Jagged1 and Dll1, for which the expression patterns in the normal hippocampus have been described previously (Stump et al., 2002). Western blots of hippocampal brain lysates from P4 animals showed no significant alteration of Dll1 or Jagged 1 in Reeler brains, compared with those of wild-type animals (Fig. 2A,B). Mean expression levels of Jagged 1 after standardization to Actin were $0.89 \pm 0.06$ for wildtype and $0.80 \pm 0.11$ for Reeler; expression levels of Dll1 were $0.79 \pm 0.14(\mathrm{wt})$ and $0.73 \pm 0.20$ (Reeler) (Student's $t$ test; $p>$ $0.5)$.

\section{NICD and thus Notch activation is reduced in the hippocampus of Reeler mice, and inhibition of Notch signaling induces a Reeler-like phenotype in hippocampal slice cultures}

Notch1 has previously been implicated in radial progenitor (radial glia) maintenance and differentiation (Gaiano et al., 2000; Patten et al., 2003, 2006; Breunig et al., 2007). However, the significance of Notch 1 cleavage during early postnatal DG development has remained an open question. Analysis of hippocampal homogenates by immunoblot revealed a $50 \%$ reduction in NICD: NEXT ratio to $0.52 \pm 0.04$ in Reeler compared with $0.93 \pm 0.04$ in wild-type animals after normalization to the highest value (Student's $t$ test; $p<0.01$ ) (Fig. $2 C$ ). Thus, Notch activation is significantly reduced in Reeler mice. Therefore, Reelin deficiency reduces Notch activation or leads to a destabilization of the NICD. Inhibition of $\gamma$-secretase phenocopies Notch mutations in zebrafish and Drosophila (Geling et al., 2002; Micchelli et al., 2003), and the $\gamma$-secretase inhibitor DAPT downregulates hes 1 and hes5 gene expression and reporter activity (Nelson et al., 2006). To investigate the role of Notch1 signaling in DG radial glial cells, we
A
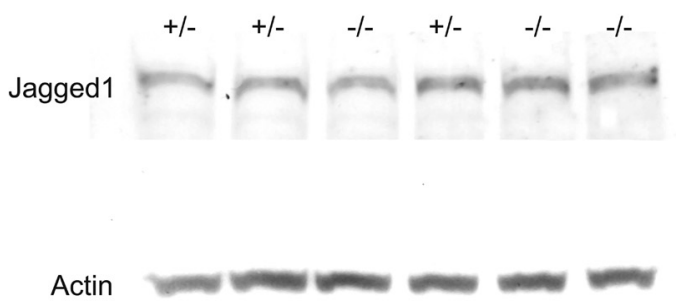

B

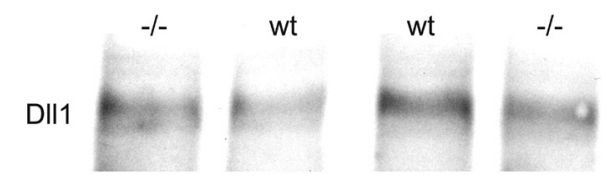

Actin
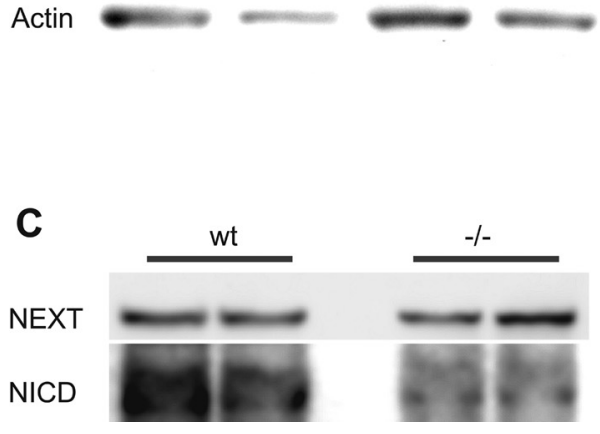

Figure 2. Western blot analysis of the Notch1 ligands Jagged1 $(\boldsymbol{A})$ and DII1 $(\boldsymbol{B})$, and NICD ( $\boldsymbol{C})$ in P4 wt, heterozygous (+/ -), and Reeler (-/-) hippocampus. Jagged1 and DII1 levels are not significantly altered in Reeler hippocampus, compared with wild-type and heterozygous animals. In contrast, the NICD is significantly diminished compared with the expression levels of NEXT. Membranes were incubated first for Jagged1, DII1, or NICD and subsequently for Actin or NEXT, respectively.

inhibited Notch1 activation in slice cultures of the hippocampus by administration of the $\gamma$-secretase inhibitor DAPT (Fig. 3).

Slice cultures were prepared from hippocampi of P0 Reeler and wild-type animals, an age at which the infrapyramidal blade of the DG is still being formed, and the existing granule cell layer continues to expand with the addition of newborn granule cells (Altman and Bayer, 1990). DAPT treatment was initiated $8 \mathrm{~h}$ after slice culture preparation, at which time point the culture medium was replaced with media containing $10 \mu \mathrm{M}$ DAPT, a concentration that has previously been reported to specifically inhibit Notch1 signaling in retinal explants without inducing cell death (Nelson et al., 2006).

After 5 DIV, glial fibers were visualized by GFAP immunostaining and antibodies against $\mathrm{NeuN}$ used to visualize neuronal cell layers and Proxl immunolabeling to visualize granule cells (Fig. 3). In Reeler DGs, analysis of the glial fiber density showed a significant $35 \%$ reduction compared with wild-type cultures $(0.9 \pm 0.03$ in wild-type cultures compared with $0.6 \pm 0.05$ in Reeler cultures). DAPT treatment of wild-type DG slices significantly decreased the mean glial fiber density to $43 \%(0.4 \pm 0.03$; $p<0.0001$; ANOVA) (Fig. $3 A, B, E$ ). In contrast, the mean density of GFAP-positive glial fibers in the CA1 region showed no apparent reduction (control, $0.9 \pm 0.05$; DAPT, $0.8 \pm 0.14$; Student's $t$ test; $p>0.5$ ), indicating that the DAPT treatment specifically inhibited putative neurogenic radial glia of the DG (Fig. 
$3 E)$. When DAPT was added to Reeler cultures no further significant decrease in fiber density was observed if compared with Reeler control cultures (data not shown). Moreover, in $70 \%$ of DAPT-treated cultures, severe granule cell dispersion had developed, reminiscent of the Reeler phenotype (Fig. 3C,D). In contrast, after Notch1 inhibition in cultures from 5-dold wild-type animals, a time point when the development of the DG is mostly complete, the radial glial fiber density as well as granule cell layering appeared grossly normal (data not shown).

\section{Inhibition of Notch activation blocks} Reelin-dependent rescue of glial growth The developmental defects in the Reeler hippocampus can be rescued in slice culture preparations by exogenous Reelin administration (Zhao et al., 2004). If Reelin regulates radial glia growth independently of Notch1 activity, rescue of fiber density by exogenous Reelin should be possible despite inhibition of $\gamma$-secretase with DAPT. Slice cultures of hippocampi of Reeler animals were treated from DIV 0 with Reelin and DMSO, Reelin and DAPT or control medium. Reelin treatment led to a significant increase $(>40 \%)$ in glial fiber density within the DG compared with control-treated slices $(p<0.001$; ANOVA). This rescue of fiber density was significantly impaired if Notch cleavage was inhibited by DAPT (Fig. $4 A-D$ ), indicating that Reelin-induced radial glia differentiation in the DG depends on $\gamma$-secretase activity (Reeler control, $0.89 \pm 0.03$; Reeler plus Reelin/DMSO, $1.3 \pm$ 0.06; Reeler plus Reelin/DAPT, $0.72 \pm$ $0.04)$.

\section{Notch 1 and Dab1 colocalize in the DG}

The results presented above demonstrate that $\gamma$-secretase inhibition and thereby inhibition of Notch 1 activation recapitulates the Reeler phenotype characterized by reduced glial fiber density and granule cell dispersion in the DG. Given that $\gamma$-secretase inhibition also hinders the Reelin-dependent rescue of glial fiber growth in Reeler slice cultures, Reelin signaling seems to depend on $\gamma$-secretase activity during DG development. Furthermore, reduced Notch1 activity in the Reeler hippocampus suggests that Reelin signaling is involved in regulating Notch1 activity during normal DG development.

What could be the actual protein-protein interactions? An interaction between Drosophila Dab and Notch was demonstrated by Giniger (1998). More recently, coprecipitation of Notch1 and Dab1, an adapter protein in the Reelin-signaling cascade, was described in a neural stem cell line and in the embryonic mouse neocortex (Hashimoto-Torii et al., 2008; Keilani and Sugaya, 2008), corroborating our results of a possible interaction of the Reelin and Notch pathways during postnatal DG development. To this end, we compared the immunohistochemical localization of Dab1 and Notch1 (Fig. 5). Dab1 and Notch1 are coexpressed in numerous cells of the dentate gyrus and neocortex and show partial colocalization (Fig. 5A-D).

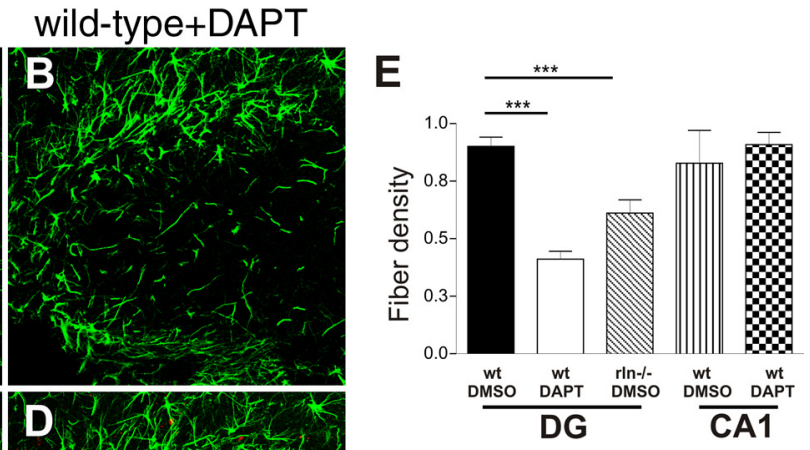

Figure 3. Inhibition of Notch1 signaling reduces radial glial fiber density. Organotypic hippocampal slice cultures from wildtype and Reeler mice were treated with DAPT to inhibit Notch1 signaling via inhibition of $\gamma$-secretase-dependent Notch1 receptor

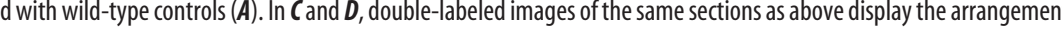

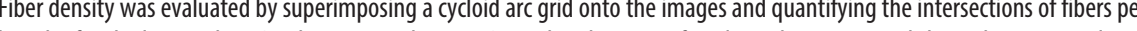
(he DG or hippocampal region CA1. Fiber densities of Reeler and DAPT-treated slice cultures are reduced compared with control slices. Evaluation of randomly selected regions within CA1 did not yield significant differences between DAPT-treated wild-type cultures and control wild-type cultures (normalized mean values + SEM; ${ }^{* *} p<0.0001$ ).

\section{Discussion}

The formation of a radial glial scaffold is indispensable for the correct formation and lamination of the hippocampal DG. During this developmental process, Reelin plays a pivotal role. The lack of Reelin in the Reeler mouse leads to severe morphological distortions: namely, the radial glial scaffold fails to form, and granule cells disperse throughout the DG (Drakew et al., 2002; Förster et al., 2002; Frotscher et al., 2003; Weiss et al., 2003). Recently, it has been shown that Reelin and Notch signaling interact in the regulation of neuronal migration and lamination in the cerebral cortex (Hashimoto-Torii et al., 2008). Given that Notch and Reelin regulate the expression of the radial glial protein BLBP (Hartfuss et al., 2003; Anthony et al., 2005), we investigated a potential cross talk between Reelin and Notch1 in postnatal DG lamination and radial glial development.

Here, we show that Reelin and Notch1 synergize during the development of the dentate gyrus, in particular in the development and maintenance of radial glial cells. In Reeler mutants, deficient in Reelin, Notch signaling is reduced as shown by a decrease in NICD and expression of Hes5 and BLBP relative to wild-type littermates. BLBP is expressed by radial glial cells, and we show that the density of GFAP-positive radial glial fibers is significantly reduced in Reeler mutants and in wild-type hippocampal slice cultures where Notch activation is blocked. Furthermore, an adapter protein in the Reelin pathway, Dab1, colocalizes with Notch1 in cells of the DG. Together, these findings show that Reelin and Notch1 not only interact during the radial migration in the neocortex as described recently (HashimotoTorii et al., 2008) but furthermore demonstrate that this interaction is essential for the development and maintenance of radial 

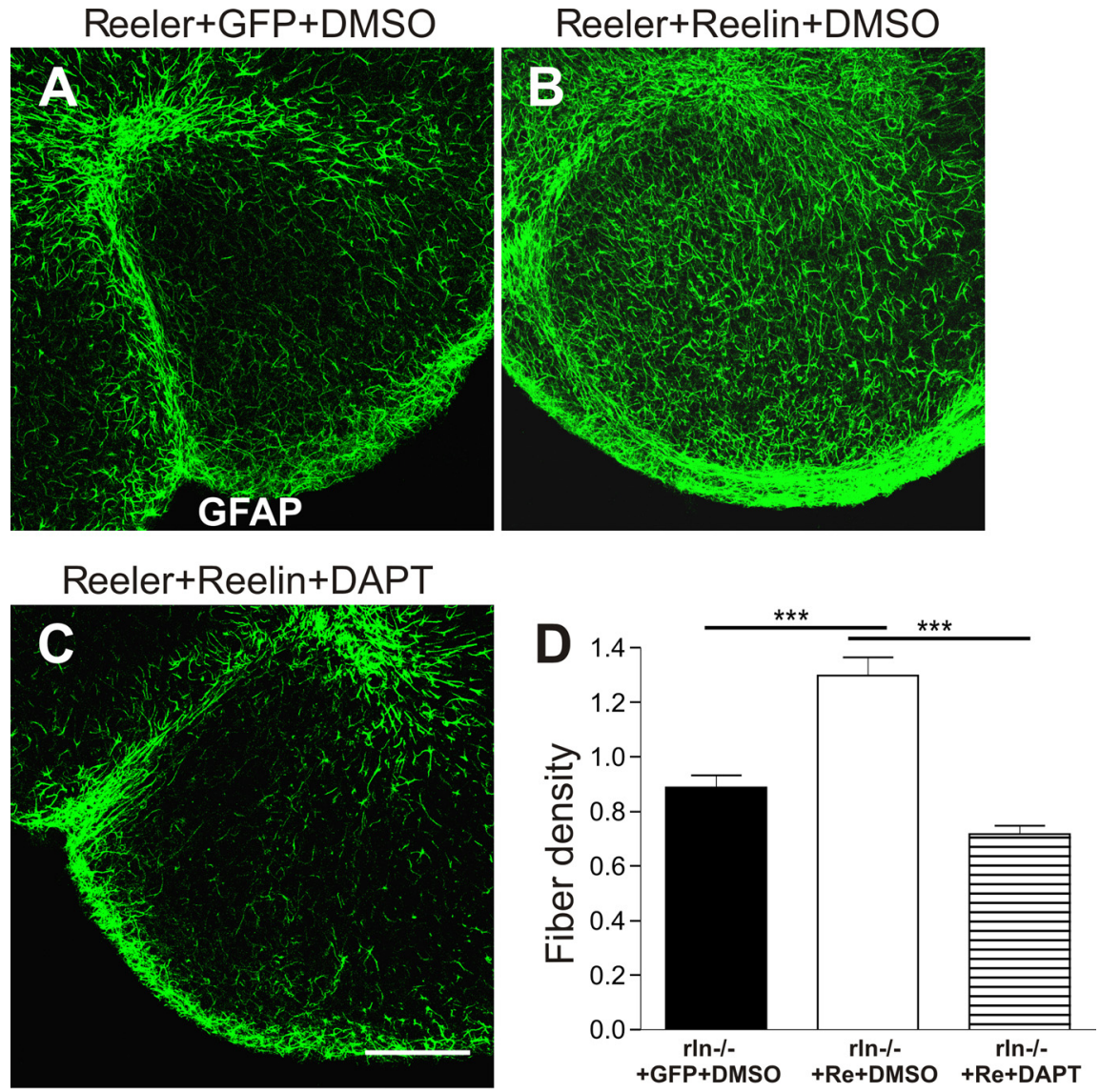

Figure 4. DAPT blocks Reelin-dependent rescue of glial fiber density. Organotypic hippocampal slice cultures from Reeler mice were treated with Reelin to rescue radial glial fiber density. Glial fibers are stained for GFAP (pGFAP; green). In $A$, reduced fiber density is apparent in Reeler slices that were treated with control medium (GFP-conditioned medium containing DMSO). Reelin administration resulted in a significant increase in fiber density $(\boldsymbol{B})$, an effect that is blocked by the addition ofDAPT to the medium (C). Images represent single laser-scanned slices in the z-plane. Scale bar, $150 \mu \mathrm{m}$. In $\boldsymbol{D}$, mean values + SEM, normalized to control, are shown $\left({ }^{* * *} p<0.001\right)$.

glial cells in the rodent DG. As GFAP-positive radial glial cells are neuronal precursors (Malatesta et al., 2000; Noctor et al., 2001; Seri et al., 2001), our results also present an important additional facet for understanding the molecular interactions controlling adult neurogenesis in the DG.

Notch1 signaling is activated in hippocampal radial glial cells In accordance with a role in radial glial differentiation, Notch 1 expression has been localized to Bergmann glial cells of the developing cerebellum (Patten et al., 2003), to radial glial cells of the embryonic ventricular zone (Tokunaga et al., 2004), and to hippocampal progenitor cells of young adult mice (Breunig et al., 2007). Here, we show the expression of Notch 1 and its cleaved intracellular domain in radial glial cells of the early postnatal DG. The expression pattern of Notch1, the colocalization of Notch 1 and BLBP, and the colocalization of NICD with GFAP suggest an involvement of canonical Notch1 signaling in the development and maintenance of radial glia in the DG. Glial cells within the molecular layer and hippocampus proper were less Notch1 immunopositive than radial glia in the hilus or subgranular layer, supporting the notion that Notch1 activity plays a pivotal role in the development of immature neurogenic glia (Tokunaga et al., 2004).
Notch1 signaling is reduced in the hippocampus of Reeler mutants Extending the findings of an interaction between Reelin and Notch in immature migratory neurons of the cerebral cortex, we show specifically Notch1 expression and activation in radial glial cells of the early postnatal DG supporting a role for Notch 1 in the regulation of granule cell generation in the hippocampus. In Reeler mutants, NICD levels are reduced in the DG as is the expression of the Notch targets Hes5 (Louvi and Artavanis-Tsakonas, 2006) and BLBP (Anthony et al., 2005). Thus, these results support previous data showing decreased BLBP expression in the neocortex of Reeler mice (Hartfuss et al., 2003). Importantly, the expression of the Notch ligands Dll1 and Jagged 1 are not altered in Reeler; hence, the reduced Notch 1 activity is not likely to be attributable to aberrant ligand binding. Together, these results show that Notch signaling is diminished in a Reelin-deficient environment.

The $\gamma$-secretase-dependent cleavage at S3 releasing NICD is constitutive during ligand binding (Struhl and Adachi, 2000). Therefore, our results suggest that Reelin may enhance Notch1 signaling in radial glia of the DG by stabilizing NICD in a similar manner to the mechanism described for radial migration of neurons in the cerebral cortex (Hashimoto-Torii et al., 2008).

Notch1 and Dab1 colocalize in the DG

Previous experiments have shown that Dab1 and Notch1 can be coimmunoprecipitated from immature neurons and neural stem cells lines (Hashimoto-Torii et al., 2008; Keilani and Sugaya, 2008), and we show that Dab1 and Notch 1 are colocalized near the cell membrane in numerous cells of the cortex and hippocampus including the putative neurogenic radial glia. Given that Dab1 can inhibit ubiquitination (Park et al., 2003), and has been described to shuttle between the cytoplasm and nucleus (Honda and Nakajima, 2006), it is possible that Dab1 could inhibit directly the ubiquitination of activated NICD. Indeed, we found evidence for a significantly increased NICD ubiquitination in Reeler animals. Therefore, the Dab1 interaction could lead to a stabilization of NICD by inhibiting ubiquitination and promoting proper development, fiber extension, and maintenance of DG radial glial cells. This is also supported by our observations that blocking Notch signaling induces a Reeler-like phenotype, including aberrant radial glial morphology and development similar to antibody block of Reelin signaling in postnatal animals (Heinrich et al., 2006). The results do not exclude that both pathways converge at other sites, including Gsk3beta, a kinase critical for Reelin signaling and reportedly inhibiting Notch-induced transcription (Espinosa et al., 2003). Additional experiments would be needed to assess if the two pathways converge at other levels. 


\section{Notch1 inhibition leads to a \\ Reeler-like phenotype}

Conditional knock-out of Notch1 in mice indicates an important role in the maintenance of radial progenitor cells during development, and mutants displayed precocious neuronal differentiation and decreased neuronal numbers (Lütolf et al., 2002; Yang et al., 2004; Yoon et al., 2004). Similarly, the proliferation of hippocampal progenitor cells in adult mice was decreased in conditional Notch mutants (Breunig et al., 2007). In Reeler, developmental defects arise as a postnatal lack of a radial glial scaffold and defective granule cell lamination (Stanfield and Cowan, 1979; Drakew et al., 2002; see also this study). We were able to mimic these Reeler-like defects by inactivating Notch signaling with DAPT applied to slice cultures from newborn animals. DAPT caused a strong decrease $(>60 \%)$ in radial glial fiber density comparable with the reduction in Reelin-deficient slices, and whereas Reelin administration to Reeler slices can rescue radial fiber length and density (Zhao et al., 2004), a rescue of the DAPT-induced defects was not observed after Reelin treatment. These results indicate that $\gamma$-secretase activity is downstream of Reelin signaling in the process of radial glial development, similar to the ability of NICD to rescue neuronal migration in the cerebral cortex of Reeler. Although $\gamma$-secretase activity is involved in the cleavage of several transmembrane molecules, including amyloid precursor protein (APP), the Reelin receptors ApoER2 and VLDLR, and Erb4 (Lee et al., 2002; Iwatsubo, 2004; Hoe and Rebeck, 2005), cells lacking the essential $\gamma$-secretase component Presenilin-1, respond to Reelin normally, excluding a direct effect on Reelin receptors in our assay. However, APP and Erb4, both expressed in astroglial cells, could contribute to the observed effects (Trapp and Hauer, 1994; Chauvet et al., 1997; Zheng and Feng, 2006). It will be important in the future to elucidate the different roles of various $\gamma$-secretase targets and their interactions in radial glial differentiation, neurogenesis, and neuronal migration in the dentate gyrus.

In conclusion, our data suggest that Reelin enhances Notch 1 activation in the DG which is necessary during an early, receptive phase of radial glial development. This interaction of Notch1 and Reelin pathways is likely to include Dabl's reduction of NICD degradation in neurogenic radial glia in the same manner as has been proposed in immature neurons. Given that Notch1 and Reelin deficiency both lead to reduced DG progenitor proliferation at older ages (Breunig et al., 2007; Zhao et al., 2007), the interaction is likely to continue in progenitor cells of the adult brain.

\section{References}

Altman J (1962) Are new neurons formed in the brains of adult mammals? Science 135:1127-1128.

Altman J, Bayer SA (1990) Migration and distribution of two populations of hippocampal granule cell precursors during the perinatal and postnatal periods. J Comp Neurol 301:365-381.

Anthony TE, Mason HA, Gridley T, Fishell G, Heintz N (2005) Brain lipid- binding protein is a direct target of Notch signaling in radial glial cells Genes Dev 19:1028-1033.

Bagri A, Gurney T, He X, Zou YR, Littman DR, Tessier-Lavigne M, Pleasure SJ (2002) The chemokine SDF1 regulates migration of dentate granule cells. Development 129:4249-4260.

Basak O, Taylor V (2007) Identification of self-replicating multipotent progenitors in the embryonic nervous system by high Notch activity and Hes5 expression. Eur J Neurosci 25:1006-1022.

Breunig JJ, Silbereis J, Vaccarino FM, Sestan N, Rakic P (2007) Notch regulates cell fate and dendrite morphology of newborn neurons in the postnatal dentate gyrus. Proc Natl Acad Sci U S A 104:20558-20563.

Chauvet N, Apert C, Dumoulin A, Epelbaum J, Alonso G (1997) Mab22C11 antibody to amyloid precursor protein recognizes a protein associated with specific astroglial cells of the rat central nervous system characterized by their capacity to support axonal outgrowth. J Comp Neurol 377:550-564.

Deller T, Drakew A, Frotscher M (1999) Different primary target cells are important for fiber lamination in the fascia dentata: a lesson from reeler mutant mice. Exp Neurol 156:239-253.

Drakew A, Deller T, Heimrich B, Gebhardt C, Del Turco D, Tielsch A, Förster E, Herz J, Frotscher M (2002) Dentate granule cells in reeler mutants and VLDLR and ApoER2 knockout mice. Exp Neurol 176:12-24.

Eriksson PS, Perfilieva E, Björk-Eriksson T, Alborn AM, Nordborg C, Peterson DA, Gage FH (1998) Neurogenesis in the adult human hippocampus. Nat Med 4:1313-1317.

Espinosa L, Inglés-Esteve J, Aguilera C, Bigas A (2003) Phosphorylation by glycogen synthase kinase-3 beta down-regulates Notch activity, a link for Notch and Wnt pathways. J Biol Chem 278:32227-32235.

Förster E, Tielsch A, Saum B, Weiss KH, Johanssen C, Graus-Porta D, Müller U, Frotscher M (2002) Reelin, Disabled 1, and beta 1 integrins are re- 
quired for the formation of the radial glial scaffold in the hippocampus. Proc Natl Acad Sci U S A 99:13178-13183.

Frey BN, Andreazza AC, Nery FG, Martins MR, Quevedo J, Soares JC, Kapczinski F (2007) The role of hippocampus in the pathophysiology of bipolar disorder. Behav Pharmacol 18:419-430.

Frotscher M, Haas CA, Förster E (2003) Reelin controls granule cell migration in the dentate gyrus by acting on the radial glial scaffold. Cereb Cortex 13:634-640.

Gaiano N, Nye JS, Fishell G (2000) Radial glial identity is promoted by Notch 1 signaling in the murine forebrain. Neuron 26:395-404.

Galceran J, Miyashita-Lin EM, Devaney E, Rubenstein JL, Grosschedl R (2000) Hippocampus development and generation of dentate gyrus granule cells is regulated by LEF1. Development 127:469-482.

Galichet C, Guillemot F, Parras CM (2008) Neurogenin 2 has an essential role in development of the dentate gyrus. Development 135:2031-2041.

Geling A, Steiner H, Willem M, Bally-Cuif L, Haass C (2002) A gammasecretase inhibitor blocks Notch signaling in vivo and causes a severe neurogenic phenotype in zebrafish. EMBO Rep 3:688-694.

Giniger E (1998) A role for Abl in Notch signaling. Neuron 20:667-681.

Haas CA, Dudeck O, Kirsch M, Huszka C, Kann G, Pollak S, Zentner J, Frotscher M (2002) Role for reelin in the development of granule cell dispersion in temporal lobe epilepsy. J Neurosci 22:5797-5802.

Hartfuss E, Förster E, Bock HH, Hack MA, Leprince P, Luque JM, Herz J, Frotscher M, Götz M (2003) Reelin signaling directly affects radial glia morphology and biochemical maturation. Development 130:4597-4609.

Hashimoto-Torii K, Torii M, Sarkisian MR, Bartley CM, Shen J, Radtke F, Gridley T, Sestan N, Rakic P (2008) Interaction between Reelin and Notch signaling regulates neuronal migration in the cerebral cortex. Neuron 60:273-284.

Heinrich C, Nitta N, Flubacher A, Müller M, Fahrner A, Kirsch M, Freiman T, Suzuki F, Depaulis A, Frotscher M, Haas CA (2006) Reelin deficiency and displacement of mature neurons, but not neurogenesis, underlie the formation of granule cell dispersion in the epileptic hippocampus. J Neurosci 26:4701-4713.

Hoe HS, Rebeck GW (2005) Regulation of ApoE receptor proteolysis by ligand binding. Brain Res Mol Brain Res 137:31-39.

Honda T, Nakajima K (2006) Mouse Disabled1 (DAB1) is a nucleocytoplasmic shuttling protein. J Biol Chem 281:38951-38965.

Iwatsubo T (2004) The gamma-secretase complex: machinery for intramembrane proteolysis. Curr Opin Neurobiol 14:379-383.

Kageyama R, Nakanishi S (1997) Helix-loop-helix factors in growth and differentiation of the vertebrate nervous system. Curr Opin Genet Dev 7:659-665.

Kageyama R, Ohtsuka T (1999) The Notch-Hes pathway in mammalian neural development. Cell Res 9:179-188.

Keilani S, Sugaya K (2008) Reelin induces a radial glial phenotype in human neural progenitor cells by activation of Notch-1. BMC Dev Biol 8:69.

Kempermann G, Jessberger S, Steiner B, Kronenberg G (2004) Milestones of neuronal development in the adult hippocampus. Trends Neurosci 27:447-452.

Lee HJ, Jung KM, Huang YZ, Bennett LB, Lee JS, Mei L, Kim TW (2002) Presenilin-dependent gamma-secretase-like intramembrane cleavage of ErbB4. J Biol Chem 277:6318-6323.

Lee JK, Cho JH, Hwang WS, Lee YD, Reu DS, Suh-Kim H (2000) Expression of neuroD/BETA2 in mitotic and postmitotic neuronal cells during the development of nervous system. Dev Dyn 217:361-367.

Liu M, Pleasure SJ, Collins AE, Noebels JL, Naya FJ, Tsai MJ, Lowenstein DH (2000) Loss of BETA2/NeuroD leads to malformation of the dentate gyrus and epilepsy. Proc Natl Acad Sci U S A 97:865-870.

Louvi A, Artavanis-Tsakonas S (2006) Notch signalling in vertebrate neural development. Nat Rev Neurosci 7:93-102.

Luque JM, Morante-Oria J, Fairén A (2003) Localization of ApoER2, VLDLR and Dabl in radial glia: groundwork for a new model of reelin action during cortical development. Brain Res Dev Brain Res 140:195-203.

Lütolf S, Radtke F, Aguet M, Suter U, Taylor V (2002) Notch1 is required for neuronal and glial differentiation in the cerebellum. Development 129:373-385.

Malatesta P, Hartfuss E, Götz M (2000) Isolation of radial glial cells by fluorescent-activated cell sorting reveals a neuronal lineage. Development 127:5253-5263.

Mayer H, Duit S, Hauser C, Schneider WJ, Nimpf J (2006) Reconstitution of the Reelin signaling pathway in fibroblasts demonstrates that Dabl phosphorylation is independent of receptor localization in lipid rafts. Mol Cell Biol 26:19-27.

Micchelli CA, Esler WP, Kimberly WT, Jack C, Berezovska O, Kornilova A, Hyman BT, Perrimon N, Wolfe MS (2003) Gamma-secretase/preseni- lin inhibitors for Alzheimer's disease phenocopy Notch mutations in Drosophila. FASEB J 17:79-81.

Nelson BR, Gumuscu B, Hartman BH, Reh TA (2006) Notch activity is downregulated just prior to retinal ganglion cell differentiation. Dev Neurosci 28:128-141.

Noctor SC, Flint AC, Weissman TA, Dammerman RS, Kriegstein AR (2001) Neurons derived from radial glial cells establish radial units in neocortex. Nature 409:714-720.

Nyfeler Y, Kirch RD, Mantei N, Leone DP, Radtke F, Suter U, Taylor V (2005) Jagged1 signals in the postnatal subventricular zone are required for neural stem cell self-renewal. EMBO J 24:3504-3515.

Park TJ, Hamanaka H, Ohshima T, Watanabe N, Mikoshiba K, Nukina N (2003) Inhibition of ubiquitin ligase Siah-1A by disabled-1. Biochem Biophys Res Commun 302:671-678.

Patten BA, Peyrin JM, Weinmaster G, Corfas G (2003) Sequential signaling through Notch1 and erbB receptors mediates radial glia differentiation. J Neurosci 23:6132-6140.

Patten BA, Sardi SP, Koirala S, Nakafuku M, Corfas G (2006) Notch1 signaling regulates radial glia differentiation through multiple transcriptional mechanisms. J Neurosci 26:3102-3108.

Raz N, Torres IJ, Briggs SD, Spencer WD, Thornton AE, Loken WJ, Gunning FM, McQuain JD, Driesen NR, Acker JD (1995) Selective neuroanatomic abnormalities in Down's syndrome and their cognitive correlates: evidence from MRI morphometry. Neurology 45:356-366.

Rickmann M, Amaral DG, Cowan WM (1987) Organization of radial glial cells during the development of the rat dentate gyrus. J Comp Neurol 264: 449-479.

Sato N, Hatakeyama S, Shimizu N, Hikima A, Aoki J, Endo K (2001) MR evaluation of the hippocampus in patients with congenital malformations of the brain. AJNR Am J Neuroradiol 22:389-393.

Seri B, García-Verdugo JM, McEwen BS, Alvarez-Buylla A (2001) Astrocytes give rise to new neurons in the adult mammalian hippocampus. J Neurosci 21:7153-7160.

Sibbe M, Frotscher M, Förster E (2007) Reelin - and Notch1 signalling cross-talk in radial glia formation. Soc Neurosci Abstr 33:455.15.

Sievers J, Hartmann D, Pehlemann FW, Berry M (1992) Development of astroglial cells in the proliferative matrices, the granule cell layer, and the hippocampal fissure of the hamster dentate gyrus. J Comp Neurol 320:1-32.

Stanfield BB, Cowan WM (1979) The morphology of the hippocampus and dentate gyrus in normal and reeler mice. J Comp Neurol 185:393-422.

Stoppini L, Buchs PA, Muller D (1991) A simple method for organotypic cultures of nervous tissue. J Neurosci Methods 37:173-182.

Struhl G, Adachi A (2000) Requirements for presenilin-dependent cleavage of notch and other transmembrane proteins. Mol Cell 6:625-636.

Stump G, Durrer A, Klein AL, Lütolf S, Suter U, Taylor V (2002) Notch1 and its ligands Delta-like and Jagged are expressed and active in distinct cell populations in the postnatal mouse brain. Mech Dev 114:153-159.

Tokunaga A, Kohyama J, Yoshida T, Nakao K, Sawamoto K, Okano H (2004) Mapping spatio-temporal activation of Notch signaling during neurogenesis and gliogenesis in the developing mouse brain. J Neurochem 90:142-154.

Trapp BD, Hauer PE (1994) Amyloid precursor protein is enriched in radial glia: implications for neuronal development. J Neurosci Res 37:538-550.

Weiss KH, Johanssen C, Tielsch A, Herz J, Deller T, Frotscher M, Förster E (2003) Malformation of the radial glial scaffold in the dentate gyrus of reeler mice, scrambler mice, and ApoER2/VLDLR-deficient mice. J Comp Neurol 460:56-65.

Yang X, Klein R, Tian X, Cheng HT, Kopan R, Shen J (2004) Notch activation induces apoptosis in neural progenitor cells through a p53dependent pathway. Dev Biol 269:81-94.

Yoon K, Nery S, Rutlin ML, Radtke F, Fishell G, Gaiano N (2004) Fibroblast growth factor receptor signaling promotes radial glial identity and interacts with Notch1 signaling in telencephalic progenitors. J Neurosci 24:9497-9506.

Zhao S, Chai X, Förster E, Frotscher M (2004) Reelin is a positional signal for the lamination of dentate granule cells. Development 131:5117-5125.

Zhao S, Chai X, Bock HH, Brunne B, Förster E, Frotscher M (2006) Rescue of the reeler phenotype in the dentate gyrus by wild-type coculture is mediated by lipoprotein receptors for Reelin and Disabled 1. J Comp Neurol 495:1-9.

Zhao S, Chai X, Frotscher M (2007) Balance between neurogenesis and gliogenesis in the adult hippocampus: role for reelin. Dev Neurosci 29:84-90.

Zheng CH, Feng L (2006) Neuregulin regulates the formation of radial glial scaffold in hippocampal dentate gyrus of postnatal rats. J Cell Physiol 207:530-539. 